Investigaciones Fenomenológicas, n. 10, 2013, 157-178.

e-ISSN: $1885-1088$

\title{
Merleau-Ponty y el giro político \\ DE LA FILOSOFÍA DEL SIGLO XX
}

\author{
Merleau-Ponty and the Political Turn \\ of Twentieth Century Philosophy
}

\author{
Mario Teodoro Ramírez \\ Universidad Michoacana de San Nicolás de Hidalgo, México \\ marioteo56@yahoo.com.mx
}

\begin{abstract}
Resumen: En este artículo proponemos ubicar el pensamiento del filósofo francés Maurice Merleau-Ponty como una de las figuras de lo que llamamos el giro político de la filosofía del siglo XX, es decir, el movimiento que radicalmente plantea el carácter original y problemático de la vida social -su movilidad extraordinaria, su contingencia extrema, el elemento siempre presente del conflicto, el involucramiento de todos los aspecto de la condición humana, etc. Partimos de la distinción entre "filosofía política" y "filosofía de lo político", explicamos particularmente el significado de esta última, enfocándolo desde un punto de vista fenomenológico. Enseguida desarrollamos los diversos aspectos de la reflexión merleaupontiana sobre lo "políti$\mathrm{Co}^{\prime \prime}$, ubicándola en el contexto general de su obra y de sus ideas filosóficas más preclaras, mostrando la consistencia de sus planteamientos básicos con el pensamiento político reciente y haciendo ver su importancia para un replanteamiento radical del sentido de lo político y del sentido de las relaciones entre filosofía y política en nuestra época.
\end{abstract}

Palabras clave: Política, fenomenología, intersubjetividad, ontología.

\begin{abstract}
In this article we identify French philosopher Maurice Merleau-Ponty as one of the key figures in what we call the "political turn" in twentieth-century philosophy, i.e. in the movement that radically confronts the original and problematic character of social life -its extraordinary mobility, its extreme contingency, the ever-present element of conflict, its involvment with all aspects of the human condition, etc.-- We start from the distinction between "political philosophy" and "philosophy of the political", concerning ourselves in particular with the meaning of the second notion, from a phenomenological perspective. We then develop several strands of Merelau-Ponty"s reflection about the "political", in the general context of his work and of his fundamental philosophical ideas, showing the consistency of his basic positions with recent political thought and showing their importance for a radical rethinking of the sense of the political and of the sense of the relationship between philosophy and politics in our era.
\end{abstract}

Key Words: Politics, Phenomenology, Intersubjectivity, Ontology. 
Yo vivo más bien en el presente, dejándolo indeciso y abierto, como él es. ${ }^{1}$

En la perspectiva de la conciencia, la política es imposible. ${ }^{2}$

Merleau-Ponty

\section{INTRODUCCIÓN}

Además del giro lingüístico, el giro hermenéutico, el giro estético, etcétera, hubo también en el pensamiento filosófico del siglo XX el giro político, esto es, una vuelta radical de la filosofía a la cuestión política y una vuelta de la filosofía sobre sí misma a partir de esa vuelta. El significado y las consecuencias de ese movimiento apenas han comenzado a desmenuzarse. En este ensayo nos proponemos destacar la importancia de la reflexión de Merleau-Ponty en la efectuación del giro político de la filosofía de las últimas décadas. Queremos mostrar que las observaciones del filósofo francés -fragmentarias y al fragor de los acontecimientos, como él mismo reconocía- no solamente resultaron cardinales para la conformación de la reflexión política posterior, sino que, adicionalmente, pueden indicarnos la vía para superar cierto impasse, cierto desconcierto en el que parece encontrarse el planteamiento y la praxis política de nuestros días.

De esta manera, ubicamos en primer lugar el contexto y el sentido de la reflexión política en nuestra época, precisando el significado de lo que llamamos el giro político. En un segundo momento damos cuenta del carácter de la filosofía de Merleau-Ponty y, particularmente, de aquel talante de su pensamiento que conecta íntimamente con la reflexión política. En un tercer momento ubicamos la concepción de la política del filósofo francés en el marco general de su reflexión sobre la "intersubjetividad". En un cuarto momento, precisamos, un paso más allá del propio Merleau-Ponty, el significado de su propuesta política. Finalmente, en un quinto momento, observamos de forma breve las consecuencias de su reflexión política en el marco de una autocomprensión del sentido actual de la filosofía.

\footnotetext{
${ }^{1}$ Maurice Merleau-Ponty, "Carta a Sartre", en Parcours deux. 1951-1961, Paris, Verdier, 2000, p. 154.

2 Maurice Merleau-Ponty, Las aventuras de la dialéctica, Buenos Aires, La pléyade, 1974, p. 219.
} 


\section{LA FILOSOFÍA DE LO POLÍTICO}

Nuestra reflexión se ubica en el campo de lo que proponemos llamar, basados en varios autores recientes, filosofía de lo político, para distinguirla de lo que tradicionalmente se ha llamado filosofía política. Mientras que esta última tiene en general un carácter normativo, es decir, se propone definir lo que debe ser una estructura de ordenación normativa y funcional de la sociedad, la filosofía de lo político busca pensar la consistencia misma de la existencia política en el marco de la vida real de las sociedades. Ahora bien, la filosofía de lo político busca además reflexionar críticamente sobre el sentido y las posibilidades del actuar político interhumano; de esta manera, se distingue también de una disciplina científica como la sociología política que se ocuparía simplemente de dar cuenta de las estructuras, las formas y los hechos de la realidad política.

Otra diferencia importante, y que tendrá implicaciones prácticas fundamentales, consiste en que la filosofía política de alguna forma se encuentra orientada teleológicamente hacia la ordenación jurídico-estatal de la sociedad, esto es, hacia la forma del Estado. Su visión de la acción política, del actuar político, está sesgada por ese telos. Por el contrario, la filosofía de lo político, en cuanto que, como trataremos de hacer ver adelante, comienza siendo más una "fenomenología de la vida política" que otra cosa, no subordina su análisis a ningún supuesto y a ningún telos preestablecido: trata, en todo caso, de ver aparecer ese telos, si aparece, en la inmanencia y la contingencia del quehacer político real de los seres humanos. La filosofía de lo político no está centrada en la noción de Estado. No está al servicio del poder estatal. Introduce, así, un elemento crítico-radical al interior del propio pensamiento filosófico. Al pensar la política el filósofo debe tener claro cuál es el propósito de su reflexión. Esto no significa que a la filosofía de lo político no le interese la comprensión del Estado (el orden normativo-institucional en general). Simplemente, busca captarlo en su realidad efectiva, como un fenómeno más, y no lo toma como un a priori de la vida social. Así, la distinción conceptual entre filosofía política y filosofía de lo político se transforma en una verdadera controversia: una controversia teórica, que anuncia ya, precipita, una controversia política, práctica.

$Y$ esto es el punto fundamental de una problematización de las relaciones entre filosofía y política y de la comprensión de la naturaleza propia e irreductible de lo político. Hasta ahora la filosofía ha tenido como condición de su ejerci- 
cio discursivo la suposición de que es posible determinar un espacio propio, al margen de la política, y que desde ese espacio se puede definir con toda precisión el ser propio de la política (y de todo lo demás). Esta suposición -la suposición de que la filosofía puede dominar a la política, o de que la política puede someterse a la filosofía- es lo que estaría en cuestión en nuestra época. El sentido y las implicaciones de este cuestionamiento quedan por precisar.

En uno de sus significados lo que llamamos el giro político de la filosofía del siglo XX tiene que ver precisamente con el desplazamiento de la clásica forma de la filosofía política hacia una filosofía más concreta y fenomenológica de lo político. Pues el giro consiste precisamente en el descubrimiento de la esencia denegada de lo político, lo que supone una puesta en cuestión de los supuestos y las intenciones típicas de la operación filosófica respecto a lo político: enmendar, corregir, reorientar, normar la vida práctica de la polis. El giro político significa, ante todo, devolver la acción política al campo movedizo y siempre problemático de las relaciones reales entre los humanos: relaciones de reconocimiento, de solidaridad, de conflicto, de poder, de pura dominación, etc. Esto es, el giro político no consiste simplemente en que la filosofía toma ahora a lo político como un tema relevante o esencial, significa, más todavía, que se descubre a la vez la irreductibilidad de lo político a la filosofía y hasta se invierte el esquema clásico: es la político, en su diferencia, en su complejidad y diversidad, lo que se convierte en una condición de la filosofía; al menos, según el esquema de Alain Badiou, en una de sus condiciones. -Quepa aclarar que se entiende aquí por "condición" no una mera relación causal (que iría de la política como realidad social a la filosofía como orden discursivo, semi-ideológico o ideológico, a la manera de la teoría de la superestructuras del marxismo mecanicista) sino el dato de que la irreductibilidad de la política es un elemento con el que el pensamiento tiene que contar y configura sus posibilidades y su propio senti$\mathrm{do}^{3}$.

Hagamos ahora un poco de historia sobre nuestro asunto. Si el primer giro político en la filosofía data de cuando Maquiavelo propuso deslindar los campos

\footnotetext{
${ }^{3}$ Cf. Alain Badiou, Manifiesto por la filosofía, Buenos Aires, Nueva visión, 1989; y Condiciones, México DF, Siglo XXI, 2003.
} 
de la moral y de la política ${ }^{4}$, el giro político en el pensamiento del siglo XX consistió, en un primer aspecto, en deslindar a la política de lo jurídico, y, en uno segundo, en deslindarla de la ideología. En el primer momento se ubica el aporte de la reflexión del controvertido Carl Schmitt ${ }^{5}$. La reflexión de Merleau-Ponty señala, desde una fenomenología radical de la experiencia en general, y de la experiencia social en particular, el punto de inflexión que lleva a la liberación de nuestra concepción de la política del dominio de la ideología, esto es, de las diversas ideologías que han cercado e intentado definir y legitimar exteriormente el ser de lo político. Si bien este movimiento implica una puesta en cuestión de las concepciones típicas de la modernidad acerca de la forma de entender y ordenar lo político, en realidad llega a poner en cuestión toda la visión filosófica de la política, desde los orígenes de la tradición occidental. Es el "racionalismo" inherente a esta tradición lo que es puesto en cuestión radicalmente -tal como lo han señalado también, desde otras perspectivas teóricas, pensadores tan distintos entre sí como Isaiah Berlin, Michael Oakeshott y Jacques Rancière ${ }^{6}$.

El gesto merleaupontiano, si bien no siempre explícitamente reconocido, se encuentra a la base de muchas posiciones y planteamientos característicos del pensamiento político de las últimas décadas. Nos proponemos demostrar esta hipótesis, es decir, mostrar la manera como el filósofo francés va delineando desde la experiencia histórica, desde su misma experiencia personal en cuanto pensador abierto al acontecimiento, una filosofía de lo político "en cuanto tal", de su realidad inconfundible, de su ser problemático, siempre inquietante, y aun así, siempre irrenunciable en cuanto rasgo constitutivo -quizá como el rasgo constitutivo- de la condición ontológica del ser humano, e incluso, ya encaminados, como condición y signo de todo pensamiento ontológico efectivo. Adicionalmente, consideramos que el pensamiento de Merleau-Ponty nos ofrece una alternativa al siempre discutible enfoque de Schmitt. Si bien ambos comparten el talante "realista", característico de todo pensador que quiera comprender esencialmente el ser de lo político, existe no obstante una diferencia

\footnotetext{
${ }^{4}$ Ver el breve pero magnífico texto de Merleau-Ponty sobre Maquiavelo, que contiene como la quintaesencia de su concepción de la política. Maurice Merleau-Ponty, "Nota sobre Maquiavelo", en Signos, Barcelona, Seix-Barral, 1964.

${ }^{5}$ Cf. Carl Schmitt, El concepto de lo político, Madrid, Alianza, 1999.

${ }^{6}$ Cf. entre otros de los textos de estos autores, los siguientes: Isaiah Berlin, Árbol que crece torcido, México DF, Vuelta, 1992; Michael Oakeshott, El racionalismo en política y otros ensayos, México DF, FCE, 1989; y Jacques Rancière, El desacuerdo. Política y filosofía, Buenos Aires, Nueva visión, 1996.
} 
radical entre la postura y perspectiva de ambos. Mientras que en Schmitt, y su descarnada asunción del espesor de lo político, el realismo no deja de estar signado por una estratagema dialéctica, que lo hace definir su postura siempre en polémica con las concepciones idealistas, lo que lo conduce, según nuestro punto de vista, a una forma de realismo que es todavía una construcción (ideológica) bajo los presupuestos que operan en todo realismo positivista básicamente, el presupuesto -metafísico- de que la "realidad" (la realidad del comportamiento político) es algo que podemos apresar a partir de ciertas definiciones y determinaciones conceptuales. Debajo de las concepciones más conspicuas de Schmitt -la definición pragmática de la soberanía como aquel que tiene la capacidad de instaurar el "estado de excepción", esto es, que ella se define más allá la estructura legal/ilegal, la especificidad de lo político en torno a la dupla amigo-enemigo (que siempre tiene a la "guerra" como su verdad final ${ }^{7}$ ) - subsiste la presuposición de la indiscutibilidad de los intereses, los deseos, las voluntades, las posiciones de los sujetos políticos, como datos o hechos incontrovertibles, y de alguna manera insuperables. El realismo político de Merleau-Ponty es totalmente de otro talante. Para captar esta diferencia tenemos que remitirnos al sentido entero de su filosofía.

\section{LA FENOMENOLOGÍA DE LO POLÍTICO}

Creemos, pues, que la filosofía y la obra de Merleau-Ponty deben ser revisitadas en el horizonte del replanteamiento actual de la política y lo político y, en particular, de lo que podemos llamar una nueva figura de las relaciones entre filosofía y política. Creemos también que el pensamiento de Merleau-Ponty nos proporciona el horizonte general para una filosofía de lo político que deberá ser llevada, como anticipábamos, al nivel mismo de la ontología y de la pregunta por el sentido y la posibilidad de la filosofía. En otras palabras, la fenomenología de lo político, que el pensador francés define y realiza en su obra, tiene implicaciones para una posible "ontología de lo político" ( y una "política ontológica"), temática que, no planteada por nuestro filósofo, nos corresponderá a nosotros delinear.

\footnotetext{
${ }^{7}$ Cf. Schmitt, op. cit.
} 
Como decimos, el punto original de la propuesta de Merleau-Ponty respecto al tratamiento de la política consiste en poner en práctica una perspectiva de análisis fenomenológico, dirigida a captar lo político en su modo de operar efectivo en la existencia humana intersubjetiva. Para entender el significado y la forma de esa fenomenología de lo político necesitamos hacer algunas aclaraciones previas sobre el significado de la filosofía de Merleau-Ponty y, en particular, sobre su peculiar interés en las cuestiones políticas, tanto histórico-concretas como teórico-filosóficas.

Vinculado desde sus inicios a la reacción a la vez anti-positivista y antiidealista de distintas corrientes de la filosofía del siglo XX (neokantismo, fenomenología, existencialismo, estructuralismo, el propio marxismo), MerleauPonty mantuvo un espíritu abierto al mundo y a su época, abierto particularmente a los avances del conocimiento científico en sus distintas ramas, a las innovaciones artísticas y literarias, y a la complejidad, opacidad y hasta oscuridad de la vida política de su momento ${ }^{8}$. Nunca se concibió como un filósofo puro ni tomó a la fenomenología como un tecnicismo de iniciados que pretendiera competir con, o redoblar a, los saberes científicos. La fenomenología era, para él, básicamente una "actitud", aquella que opera bajo la consigna de "ir a las cosas mismas" y que no tiene otro principio que el de atenerse a la experiencia de la cosa, es decir, todo aquello que sea el caso ${ }^{9}$. Para el fenomenólogo francés, todo puede ser experienciado, aun de modo indirecto, aun las realidades indirectas, ajenas o lejanas (en tanto que tales, es decir, en su ajenidad, en su lejanía). "Fenomenología" significa asumir el mundo tal como sea da, sin anteponerle una razón o una verdad previas, ya constituidas en sí y por sí mismas, y de las que el fenómeno sería solamente una ejemplificación o una realización. No hay nada antes o más allá del fenómeno, del conjunto de apariciones que van mostrando el ser de una cosa o la efectividad de un hecho. Si hay un logos -el logos de la fenómeno-logía-, él emerge espontáneamente en el encadenamiento inmanente de los fenómenos, y este encadenamiento "se da" para alguien y en cierto momento, bajo cierta perspectiva y en cierto contexto. No hay visión de sobrevuelo ni perspectiva privilegiada. Ahora bien, es cierto

\footnotetext{
${ }^{8}$ Cf. nuestro texto: Escorzos y horizontes. Maurice Merleau-Ponty en su centenario (1908-2008), Morelia, Jitanjáfora, 2008.

${ }^{9}$ Cf. la auto-exposición y auto-comprensión que Merleau-Ponty hace de su concepción de la filosofía fenomenológica en el "Prólogo" a su obra magna: Fenomenología de la percepción, Barcelona, Península, 1977.
} 
que la fenomenología, desde el planteamiento husserliano, se propone, a través del campo fenomenológico, una labor de constitución eidética, en cuanto fundamento racional del acto cognoscitivo. Pero por más evidencia y plenitud que logren esas "esencias", desde el momento que aparecen como los focos o las "articulaciones" de un "campo fenomenológico", no podrán considerarse más como entidades supra-mundanas, prístinas y acabadas, allende al mundo. En fin, como apunta Merleau-Ponty, una fenomenología consecuente tiene que admitir que el campo eidético es derivado y no fundante, que no es lo primero, y que, más bien, él se apoya, como todos nuestros saberes y proyectos prácticos, en nuestra experiencia viva, inmediata y concreta del mundo. Esto vale, y de manera absolutamente pertinente, para el "campo político", el campo fenomenológico por excelencia, en cuanto espacio incierto, variante, móvil, siempre insatisfactorio, al menos en comparación con las expectativas del pensamiento clásico y sus requerimientos de certeza, fijeza, inmutabilidad, definición precisa de lo que es y de lo que no. Todo ese orden duro, todos esos parámetros inamovibles se encuentran cuestionados en la experiencia política, y en la experiencia socio-cultural en general, desde el pasado siglo y hasta nuestros días. Nuestro mundo se volvió por entero fenomenológico, y no sólo en teoría.

En cuanto Merleau-Ponty invierte el esquema husserliano experiencia-eidos y coloca a las esencias como derivadas, relativas $y$, por ende, tan inciertas e inacabadas como los hechos mismos, marca su raya respecto a las intenciones todavía idealistas e intelectualistas del fundador de la fenomenología. La razón no es una base que una vez puesta pueda ofrecernos pautas incontrovertibles para ordenar y guiar los fenómenos del mundo y las posibilidades de nuestra acción en él y con los demás ${ }^{10}$. Todo se vuelve borroso, brumoso. Para Merleau-Ponty, la razón es tan contingente como el propio mundo. Contingencia es la palabra que mejor capta nuestro "ser-en-el-mundo" y nuestro quehacer en él. Es también la palabra que mejor expresa el rasgo fundamental de la vida política como el lugar de la coexistencia interhumana. Nada hay escrito ni predeterminado ahí. Esta dimensión intrínsecamente política de la existencia colectiva es algo que el fundador de la fenomenología -Edmund Husserl- pudo observar si acaso de lejos y no afectó esencialmente sus concepciones antropológicas y

\footnotetext{
${ }^{10} \mathrm{Cf}$. los textos donde el fundador de la fenomenología expresa paradigmáticamente su concepción más o menos "racionalista" de la cultura y la acción social: Edmund Husserl, La filosofía como ciencia estricta, Buenos Aires, Nova, 1973; y Renovación del hombre y de la cultura, Madrid, Anthropos / UAM, 2002.
} 
socio-culturales. Por el contrario, la cuestión política nunca dejó de estar a la vista de Merleau-Ponty y de motivar continuamente su inquietud filosófica. Ahora bien, sería contradictorio con su perspectiva suponer algún tipo de relación causal entre política y filosofía. Más bien podríamos hablar de un juego de espejos, donde ambas instancias se reflejan una a otra, se determinan entre sí, se traslapan y confunden, y en algunos momentos hasta se esclarecen mutuamente, ayudando así a mejorar nuestra visión y nuestra comprensión de los asuntos en cuestión. Dice Merleau-Ponty: "La filosofía y la política son solidarias $^{\prime 11}$. Trataremos de precisar esta interacción, esta reversibilidad y solidaridad filosofía-política, haciendo una breve relación de los temas y las ideas de la reflexión política merleaupontiana en el contexto de sus ideas filosóficas características.

\section{LA DESAZÓN POLÍTICA, EL MUNDO INTERHUMANO}

"No creo que se pueda hacer una sociedad, ni una política, ni, con más razón, un arte, a fuerza de "imperativos". Toda política seria reposa sobre un análisis de la situación local y mundial, ella traduce eso que quiere el tiempo" ${ }^{12}$. Para nuestro filósofo, la política vive al ras del acontecimiento, es el ámbito mismo de la inmanencia, de la secularidad, del "tiempo". -Según una noción de tiempo que es quizá más cercana al uso climatológico o meteorológico que al cronológico, como cuando se dice "cómo está el tiempo", "qué tiempo tenemos", es decir, el "tiempo" como probabilidad atmosférica, como "contingencia". El mundo humano, interhumano, el mundo de las relaciones interpersonales, de la intersubjetividad, que es el mundo de la historia y de la praxis político-social conforma una especie de atmósfera donde juegan una infinidad aleatoria e imprevisible de elementos, sobre el cual, al igual que el tiempo del clima, sólo podemos saber y predecir algo de manera incierta y para un periodo muy breve. Este tiempo es el tiempo del presente, el tiempo que tenemos y somos, el tiempo del "momento". Ahora bien, es en "la exuberancia y el espon-

\footnotetext{
${ }^{11}$ Maurice Merleau-Ponty, Parcours deux, op. cit., p. 303.

12 Merleau-Ponty, op. cit., p. 69.
} 
jamiento del presente" ${ }^{13}$, escribe Merleau-Ponty, donde se juega esencialmente nuestra existencia, nuestra acción y nuestra libertad; donde, ante todo, ha de posicionarse una política "seria", adecuada, es decir, una política que rehúya el imperativo, los dictados, las órdenes; que quiera comprender antes que mandar e imponer; que está abierta al acontecimiento, a la contingencia, al devenir.

Con esta consigna, y en una época crucial como ninguna en la historia, Merleau-Ponty se aboca a interrogar el mundo histórico-social y a buscar entender el ser propio de lo político. De esta tarea surgen dos libros, los típicamente políticos de su reflexión: Humanismo y terror (de 1947) ${ }^{14}$ y Las aventuras de la dialéctica (de 1955) ${ }^{15}$. Ciertamente, la reflexión política está presente en muchos otros textos del filósofo: artículos, entrevistas, encuentros, ensayos en otros libros ${ }^{16}$, etcétera; de alguna forma, está latente en su entera reflexión sobre la intersubjetividad, la experiencia humana $y$, en general, sobre la forma de nuestras relaciones con el Ser. Una idea que se entrelaza en las dos obras mencionadas es la de la opacidad de la vida socio-política. Contra todas las pretensiones racionalistas de "dirigir" la praxis interhumana -pretensiones que cabe atribuir por igual al liberalismo y al marxismo (en general, a toda ideología política, desde el fascismo hasta el formalismo jurídico)-, el filósofo francés constata con perspicacia y a cada momento el "maleficio", la "condena", de la coexistencia humana. Dado que no hay, como en la naturaleza, leyes que rijan y den cuenta de la acción humana ${ }^{17}$, y dado que tampoco existe una transparencia de las conciencias entre sí -el principio de la "encarnación" prohíbe esa posibilidad incluso para la propia conciencia individual (no hay cogito, es decir, pensamiento puro)-, esto es, dado que no hay un espíritu universal, una conciencia trascendental, el mundo de las relaciones interhumanas está lejos de ser un mundo donde la armonía, la concordancia, la confluencia, el sentido común, y la vida regida por valores y sentimientos positivos (respeto, autonomía, rectitud, justicia, entendimiento, solidaridad, amor, etc.) sea de principio posible. La encarnación de cada conciencia, su ser ineludiblemente una con su

\footnotetext{
${ }^{13}$ Op. cit., p. 113.

${ }^{14}$ Cf. Maurice Merleau-Ponty, Humanismo y terror, Buenos Aires, La pléyade, 1968.

${ }^{15}$ Cf. Maurice Merleau-Ponty, Las aventuras de la dialéctica, Buenos Aires, La pléyade, 1974.

${ }^{16}$ Cf., además de los textos ya citados de Merleau-Ponty: Sentido y sinsentido, Barcelona, Península, 1977.

${ }^{17} \mathrm{O}$ no nos es posible conocerlas.
} 
realidad corporal y sensible, la necesaria finitud y parcialidad de toda experiencia y de toda perspectiva (sensible, ideológica, teórica, histórica, filosófica incluso) sobre el mundo, imponen con tozudez la evidencia de la opacidad, de la posibilidad del conflicto, la divergencia, la simulación, el fracaso, la guerra incluso, como tramas y efectos de la vida colectiva. No obstante, Merleau-Ponty no es un pesimista, no es un nihilista.

Claramente, no es un "sustancialista". No cree que haya ningún tipo de sustancialidad; particularmente, no hay una "sustancia social", algún tipo de estructura maciza y autoevidente que definiera con precisión las condiciones y posibilidades de la acción social. A diferencia de las posturas liberales, incluidas las posturas del realismo político a la manera de Carl Schmitt, Merleau-Ponty no determina ninguna forma de sustancialidad, ni la de un ente colectivo, un ser común con identidad y hasta personalidad propia, ni la de un ente individual, constituida en torno a un supuesto núcleo imperecedero del sujeto individual (su interés, su deseo, su identidad: el monadismo típico del liberalismo). No hay, en general, sustancialidad en la realidad humana: ya se conciba esa realidad como una entidad biológica, psicológica, sociológica, espiritual. -No hay una esencia humana, no hay "humanidad" como un carácter o un rasgo predefinido e inmutable. Lo que hay son sólo relaciones, haces de relaciones. El individuo, como cualquier otro componente de una estructura (la estructura de la vida socio-política en este caso), posee, ante todo, una existencia diacrítica: se define y se capta a sí mismo en el juego de sus relaciones con otros como él, con los que lo rodean y con los que están más allá y de modo indirecto determinan su posición y lugar. Para dar cuenta de esta realidad viva e incomparable, el filósofo -Merleau-Ponty- se ve en la necesidad de ceder las palabras finales de su obra magna al escritor -Antoine de Saint-Exupéry-, cuando éste dice: "El hombre no es más que un nudo de relaciones, las relaciones son lo único que cuentan para el hombre ${ }^{\prime 18}$.

La intersubjetividad es originaria, es primera. Pero no consiste, insistimos, en una pluralidad de sujetos, de entes individuales interrelacionados, donde cada uno se capta a sí mismo plenamente e independientemente de los otros, a partir de lo cual establece relaciones claras y distintas con los demás. Esto sólo pertenece al nivel de la fórmula oficial y declarada de la intersubjetividad. Por

${ }^{18}$ M. Maurice Merleau-Ponty, Fenomenología de la percepción, op. cit., p. 463. 
debajo de ella, en su realidad concreta, las interrelaciones interhumanas constituyen un verdadero "magma"19 de relaciones, de movimientos, anticipaciones, interpretaciones, reacciones, reconfiguraciones, recorridos de ida y vuelta... La "comunidad humana" es una ramificación, un entrecruzamiento, un "rizoma", es decir, una pluralidad en movimiento, una potencia que conecta aleatoriamente consigo misma y que está abierta a un porvenir siempre efectivo aunque nunca acabado y unívoco.

Pero la intersubjetividad, hemos dicho, tampoco puede ser pensada como una estructura anónima, sólida, que asigna inequívocamente a cada cual su lugar y función en el sistema. Para Merleau-Ponty la intersubjetividad es la existencia misma, la co-existencia; es co-ser a-ser, antes que ser sido. No es exactamente una relación de sujetos, una "inter-conciencia"; es, más bien, "intercorporedidad", esto es, relaciones entre cuerpos vivientes, formación de una corporalidad general, anónima, una carne del mundo-; es "intersensorialidad" esto es, existencia de una sensibilidad común, un sentir desparramado que se concreta aquí y allá, un sensorium que es el único dato de la humanidad que podemos definir con cierta certeza. Son sintomáticas las palabras que MerleauPonty utiliza para describir el mundo de las relaciones interhumanas: superposición, usurpación, encabalgamiento, promiscuidad, reversibilidad, entrelazamiento, quiasmo... Todo ellos hacen referencia a una experiencia de la intersubjetividad como experiencia de una disolución, de un devenir continuo que dispersa toda identidad fija, antedatada, a priori. Si hay identidad, ésta se encuentra siempre en juego, y en el juego de las relaciones y los intercambios. El ejemplo más claro de esta disolvencia de lo fijo lo encontramos en el diálogo, en el encuentro, corporal y lingüístico, con el otro. A diferencia de las cosas, explica Merleau-Ponty, ante el otro:

Ya no me contento son sentir: siento que me siente, y que se me siente mientras estoy sintiendo, y mientras estoy sintiendo ese mismo hecho de que se me siente... No sólo hay que decir que habito en adelante otro cuerpo: esto no sería sino un segundo yo mismo, un segundo domicilio para mí. Sino que hay un yo que es otro,

19 Sobre el uso de la palabra magma por Merleau-Ponty, ver: Notes de cours. 1959-1961, établi par Stéphanie Ménasé, préface de Claude Lefort, Paris, Gallimard, 1996, pp. 211-213. 
que tiene su sede en otra parte, y me destituye de mi posición central, por más que, con toda evidencia, sólo de su filiación pueda extraer su cualidad de yo. ${ }^{20}$

Somos constitutivamente, ontológicamente, mezclados, imbricados con los demás, relativizados. Somos con los otros, entre los otros, en los otros.

Ahora bien, la problematicidad de las relaciones interhumanas es una manera neutra de nombrar nuestra libertad. La libertad que nos constituye y que es más efecto de nuestra estructura ontológica -nuestro "ser-al-mundo"- que rasgo de una voluntad o atributo de una decisión (de una conciencia, de un "para sí", a la manera sartriana). Todavía más, "libertad" es el nombre de la estructura ontológica de lo existente $\operatorname{mismo}^{21}$, al menos fenomenológicamente captado (¿hay otra forma?). En tanto que tal, la libertad no nos predetermina a nada (obviamente). No estamos condenados al entendimiento y al logro, al bien, pero tampoco, y por la misma razón, al desencuentro, al fracaso, al mal. Entre la pureza de un ser "para sí", una conciencia dueña en todo de sí misma y que sobrevuela el mundo, y la positividad de un "en sí" todo compacto, que no deja lugar a la indeterminación, a la duda, y que tiene ya previstas todas las respuestas, se encuentra una zona intermedia que Merleau-Ponty buscó en todo momento vislumbrar, en llamar la atención sobre ella. Es el intermundo, "este intermundo que Ilamamos historia, simbolismo, verdad por hacerse"22, y que nuestro filósofo opone al esquema del Ser y la Nada de Sartre; que opone por igual a la dialéctica objetiva -ya hecha en las cosas y que sólo debemos constatar- que defienden los materialistas, como a la dialéctica subjetiva -que sólo se realiza en la conciencia y en los actos del pensar- por la que abogan el voluntarismo y el individualismo. No estamos determinados, nuestro ser no es simplemente el resultado mecánico de lo que ha sido; pero nuestra libertad no es pura, incontaminada: se hace en una situación y reasumiendo lo que le antecede: nuestra historicidad, el mundo social y sus instituciones, las tendencias y orientaciones de la época, las prefiguraciones de la acción colectiva. Se trata, en primer lugar, de realidades complejas, que no están simplemente ahí dadas, y a las cuales hubiera que engancharse sin más; no nos dicen nada si no las interrogamos, si no las entendemos con un pensamiento comprensor (si no las

\footnotetext{
${ }^{20}$ Maurice Merleau-Ponty, La prosa del mundo, Madrid, Taurus, 1971, p. 196.

${ }^{21}$ Cf. Jean-Luc Nancy, La experiencia de la libertad, Barcelona, Paidós, 1996.

22 Maurice Merleau-Ponty, Las aventuras de la dialéctica, op. cit., p. 226.
} 
interpretamos y actualizamos en una acción que es presente). Y tal es la primera forma en que se manifiesta la libertad: como la exigencia de comprender y, así, de comprenderse a sí misma, de reconocerse ella misma en el mundo móvil y errante que la anticipa y la requiere desde la forma difusa e indeterminada, indecisa, de su ser más propio. Libertad es la "fenomenalidad" misma.

Concebido de esta manera el mundo interhumano -como el mundo donde las relaciones e interrelaciones, las acciones, son lo primero, lo que cuenta, como mundo ambiguo, cuasi-encantado, de la indeterminación y la aperturano puede ser sino un mundo político. "Política" es el nombre de la vida concreta y real de la intersubjetividad: el carácter de la condición humana. Antes que lucha por el poder, por el interés o por el reconocimiento, la política es simplemente el nombre del espacio de la coexistencia, el ser de lo humano, es el lugar de la lucha por la existencia, es decir, donde la existencia se realiza y lucha por mantenerse y desarrollarse en tanto "existencia": nuestro modo de ser en el mundo, de ser con los otros y para nosotros mismos. Ahora bien, desde esta condición primigenia y básica, propiamente ontológica, lo político pone ciertamente en juego todos los aspectos particulares de la coexistencia humana: los intereses, el deseo, las pasiones, la inteligencia, el poder, los valores, los proyectos, las ideologías, la reflexión teórica, las utopías incluso -todo juega en lo político, pero todo y cada cosa, cada dimensión, cuenta en tanto que se "fenomenologiza", es decir, en cuanto adviene fenómeno, forma y figura de la existencia concreta, manifestada en acciones, expresada en conductas, mostrada en actitudes, en diálogos, en coordinaciones, en movimientos y procesos concretos. Nunca fue obvio que la representación política implicara necesariamente la separación, la extracción, entre el "representante" y lo "representado". El proceso político efectivo es él mismo su propia representación. Lo político queda recuperada al nivel mismo de la acción, de la vida concreta, con sus mil fulguraciones y mil posibilidades. En fin, fenomenologizar lo político quiere decir ante todo desenajenar la acción política. Regresar la política a la comunidad entera, al pueblo real y existente, a la vida. Esto es democracia fenomenológica: democratizar la fenomenología y fenomenologizar la democracia. 


\section{LA DESENAJENACIÓN POLÍTICA}

Estamos yendo, pues, un paso más allá de Merleau-Ponty. No obstante, creemos que nos es un paso incongruente con el sentido y las intenciones profundas de su pensamiento, de su búsqueda; nos ubicamos pues en lo propio "impensado" de Merleau-Ponty: la posibilidad de una política, su sentido y alcance.

Como pensador crítico, como buen fenomenólogo, Merleau-Ponty llegó en un momento a recomendar, como hiciera el propio Descartes, una especie de "política provisional" (Descartes hablaba de "moral provisional"). Después de constatar la caída de las grandes ilusiones ideológicas, la crasa incongruencia de las ideologías existentes (el liberalismo, el marxismo, el propio "existencialismo"), los límites de toda política oficial (estatal), los peligros mortales de toda clase de dogmatismos, la exasperación de las vidas en la búsqueda de sentido y valor frente a un mundo cogido por la ambivalencia y el extrañamiento de los valores, por la "imposibilidad", Merleau-Ponty recomienda -ante todo para sí mismo- una especie de "abstención responsable", no una falsa neutralidad ideológica, sino una puesta en práctica de la capacidad de la mente reflexionante para permanecer atenta a las recaídas, los engaños y las manipulaciones. Llegó a recomendar lo que después el teórico italiano de la política Roberto Esposito llamó lo "impolítico": una práctica activa de la crítica de la política existente, un "compromiso" con la acción política que no renuncia a la reflexión, a la interpretación ni a la toma de posición ${ }^{23}$. No es "apolítica", es decir, renuncia ilusoria a la política. En principio Merleau-Ponty piensa la posibilidad de lo político bajo el signo y el sentido de una negatividad irrenunciable (a la manera de Adorno). No habló propiamente de "impolítica" pero sí de la opción del "a-comunismo". Lo mismo llegó a hacer en el plano de la filosofía: no negar simplemente la otredad del pensamiento, lo otro de la filosofía, sino plantear una comprensión de la filosofía como siendo a la vez, y necesariamente, "afilosofía". ¿Qué significan estas opciones, y cómo puede desprenderse de ellas algún tipo de comprensión positiva, que no nos deje simplemente en la distan-

\footnotetext{
${ }^{23}$ Cf., entre otras de sus obras, de Roberto Esposito, Comunidad, inmunidad y biopolítica, Madrid, Herder, 2009.
} 
cia e incluso en cierta pasividad, cuidadosa, prudente, pero pasividad al fin? Es la interrogación que queremos dirigir a nuestro filósofo.

Frente a la alternativa imperiosa que durante la época de la guerra fría se les planteaba a él y sus contemporáneos de identificarse acríticamente bien con el capitalismo -los Estados Unidos- o bien con el comunismo -la URSS-, Merleau-Ponty llega a la conclusión de que estas alternativas en blanco o negro son estrategias de guerra y que constituyen la negación, al fin, de la política, de la coexistencia, de la sobrevivencia incluso. Si el asunto consistiera en elegir entre lo que cada opción declara oficialmente acerca de sí misma no habría problema para la elección, cualquiera que ésta fuera. El problema estriba en que capitalismo y comunismo son realidades históricas, contingentes, antes que conceptos o ideas. Ciertamente podríamos asumir y reconocer la superioridad ideal, moral, del comunismo. Pero la política no es un reino de ideas e ideales, sino un mundo práctico, complejo y abierto donde nada podemos decir que sabemos con certeza. Merleau-Ponty llega, así, a una "conclusión agnóstica". Y precisa: "el agnosticismo, a pesar de las palabras, es aquí una conducta positiva, una tarea, así como la simpatía, por el contrario, es una abstención"24. Consigna desconcertante, sin duda. Es que, precisamente, la "simpatía" y la "antipatía" (el "compromiso" incluso ${ }^{25}$ ) no son actitudes políticas, no pertenecen en verdad al mundo propio donde se desenvuelve la política, que es acción efectiva, siempre situada, siempre dudosa. Siempre "comprometida" más allá de todo lo que pueda decirse discursivamente, pero siempre menos de todo lo que un proyecto ideal puede reclamar. En el margen de la política efectiva, la "simpatía" es una forma de desinteresarse y distanciarse de las cosas del mundo preservando para sí mismo la idea de una posición supuestamente libre, superior y siempre correcta. Por el contrario, el agnosticismo -como postura política y no como postura epistemológica-, en cuanto es necesariamente relativo, contextual y provisional ("no sé ahora: veremos luego"), es una mirada, una posición a ras de los hechos, que queda prendida a ellos, comprometida con ellos de modo tal que ninguna postura bien definida lograría nunca. No soy esto, no soy eso, no soy aquello, pero tampoco nada más. Me muevo de un punto a otro, capto un

\footnotetext{
24 Maurice Merleau-Ponty, Las aventuras.., op. cit., p. 209.

25 "El compromiso pertenece a un orden totalmente distinto que el de la acción histórica y política, la cual circula bajo las situaciones y los hechos, concede esto para obtener aquello, y justifica los detalles por el conjunto". Merleau-Ponty, op. cit., p. 216.
} 
dato, y otro más. No hay manera de sobrevolar el mundo para tener el "punto de vista justo", permanezco en un buen y activo agnosticismo. Más concretamente, Merleau-Ponty, habla de la opción del "a-comunismo", ni pro-comunista -que obvia los equívocos del socialismo- ni anti-comunista -que se somete sin más a la política guerrera del capitalismo. "El a-comunismo -explica nuestro filósofo- nos obliga (y solamente nos obliga) a tener una política positiva, a plantear y resolver los problemas concretos, en lugar de vivir con un ojo fijo"26 en cada una de las alternativas. El a-comunismo es una política perfectamente real, más real y concreta que la de cualquiera de las identificaciones convencidas, de las polaridades impuestas. Es la política misma en cuanto ella tiene que ser y es algo más que lucha ideológica, confrontación decisiva, guerra al adversario, imposición de soluciones definitivas, dominación sin más.

Así pues -el asunto conceptual de fondo-, la negatividad no es, ciertamente, "algo", no puede positivizarse, asumirse como una posición objetiva; pero tampoco es una pura nada, un vacío, una ausencia pura, al fin, de alguna manera y paradójicamente, sustancializada. Se trata, más bien, como dice Merleau-Ponty hablando en el nivel ontológico, de una "ausencia circunscrita" (no es esto, ni eso, ni aquello), tan problemática y dudosa como lo el mismo ser que niega. Tal es la paradoja del proceso político y del proceso histórico en general; el problema de la dialéctica, la dificultad del devenir histórico. En su evaluación crítica del pensamiento y la política marxista, Merleau-Ponty llega a la conclusión de que es la idea misma de revolución, de negatividad revolucionaria lo que resulta problemático, intrínsecamente equívoco ${ }^{27}$. Pues, "como es evidente, no existe un equivalente positivo de la negatividad y sus representantes son tan positivos como es posible serlo" ${ }^{28}$. En el momento que la negatividad se positiviza, se estatuye -en una línea, una dirigencia, una ideología, un gobierno-, entonces se niega a sí misma, se falsifica y traiciona: "las revoluciones son verdaderas como movimientos y falsas como regímenes" ${ }^{29}$, asienta con contundencia nuestro filósofo. Todos los problemas por los que atravesó la práctica comunista pueden entenderse a partir de esta observación. La contradicción inmanente que porta la idea de revolución, y que pone en cuestión no solamen-

\footnotetext{
${ }^{26}$ Op. cit., p. 209.

27 Ibíd., p. 86.

${ }^{28}$ Ibíd., p. 104.

${ }^{29}$ Ibíd., p. 236.
} 
te la viabilidad de un régimen revolucionario -que termina convirtiéndose necesariamente en una dictadura- sino la concepción misma del proyecto revolucionario. "La revolución y su fracaso serían la misma cosa" ${ }^{30}$, asesta nuestro filósofo. No hay una dialéctica en la historia, ya definida -como creía el propio Marx- y ninguna sociedad puede cambiar más allá de lo que sus propias condiciones objetivas lo permitan (como también creía el propio Marx). "A partir de esto se plantea el problema de si no hay mayor porvenir en un régimen que no pretende rehacer la historia desde su base, sino solamente cambiarla, y no es ese régimen el que debemos buscar, en lugar de entrar una vez más en el círculo de la revolución" ${ }^{31}$. Este régimen no es otro, pues, que la democracia, el poder parlamentario. Aún con todos sus defectos -con su intención de diluir las posiciones, los conflictos reales, la lucha de clases-, la democracia sigue siendo el único régimen político que deja espacio a la política, o, al menos, el único que deja subsistir en su seno la lucha entre la política y la anti-política. Merleau-Ponty no era crédulo respecto a las virtudes de la democracia. Dice en un momento: "la debilidad del pensamiento democrático se debe a que este pensamiento es menos una política que una moral" ${ }^{32}$. Y la alternativa que plantea es su premisa: "sabemos hoy que la igualdad formal de los derechos y la libertad política ocultan las relaciones de fuerza más que suprimirlas. Y el problema político es entonces el de instituir estructuras sociales y relaciones reales entre los hombres de manera que la libertad, la igualdad y el derecho sean realmente efectivos" ${ }^{\prime 33}$.

Este es el meollo, simple y evidente en sí mismo, de la postura política merleaupontiana, éste es el aspecto del marxismo que siempre valoró: de lo que se trata es de transformar las relaciones reales entre los humanos, de llevar los valores a la praxis, de fundar y construir en la realidad de la historia un mundo nuevo. No de teorizarlo, de ideologizarlo; no de decirlo sino de hacerlo. "La maldición de la política consiste precisamente en esto: que debe traducir los valores en el orden los hechos" ${ }^{34}$. Una política de las ideas, una política ideal, en el puro nivel de la ideología y la creencia, es una contradicción en los térmi-

\footnotetext{
${ }^{30}$ Ibíd., p. 248.

${ }^{31}$ Ibíd., p. 236.

32 Merleau-Ponty, Sentido y sinsentido, op. cit., p. 162.

33 Merleau-Ponty, op. cit, 162.

${ }^{34}$ Merleau-Ponty, Humanismo y terror, op. cit., p. 29.
} 
nos. La política pertenece al ámbito de la praxis, de la vida real, de la posibilidad efectiva. Pero este realismo político no es absoluto, no acepta todo por igual: matiza, precisa. Merleau-Ponty se explica: "Hemos dicho que una política no puede justificarse por sus buenas intenciones. Se justificará menos aún por intenciones bárbaras. Nunca dijimos que toda política que triunfa fuera buena. Hemos dicho que una política para ser buena tiene que triunfar. Nunca dijimos que el triunfo santificase todo; hemos dicho que el fracaso es una falta o que en política no existe el derecho a equivocarse, y que sólo el éxito torna definitivamente razonable lo que al principio era audacia y $\mathrm{fe}^{\prime \prime 35}$. La política pertenece al ámbito de la creación, de la invención; como se ha dicho siempre, es el arte de lo posible. Hay que subrayar ahora no sólo la palabra posible sino también la palabra arte. Cierto, a diferencia de lo que normalmente llamamos arte, la política no crea un objeto, una obra, o más bien: su obra son relaciones, configuración y reconfiguración del mundo humano concreto.

\section{ONTOLOGÍA POLÍTICA}

Si el mundo político está más acá de toda sustancialidad, si es el reino inasible de la contingencia, la relatividad y la innovación inesperada, entonces está más allá de cualquier determinación de su ser y su posibilidad en términos ya de un conflicto irreductible o ya de un consenso idealizante, pues ambas concepciones -las típicas, en su contraposición, del pensamiento político del siglo XX- pecan todavía de querer predeterminar la existencia política en torno a un definición al fin teórica, ideológica, y no real, fenomenológica. Ahora bien, tanto el ideal del acuerdo puro como la supuesta constatación del desacuerdo total son contradictorias con nuestra noción más elemental de política (y de democracia): el primero conlleva la anulación de la diversidad de posturas e intereses, el segundo olvida que aun el desacuerdo supone un mínimo suelo común, indeciso, difuso, que no garantiza de suyo la superación de la discordancia pero que tampoco simplemente nos condena a permanecer fijos en ella. No hay pelea de box sin ring. No hay discusión sin ágora. Y la discusión sólo se termina cuando alguien recurre a medios extra-políticos (violencia directa) para

\footnotetext{
${ }^{35}$ Merleau-Ponty, Op. cit., pp. 28-29.
} 
imponer su punto de vista. Tal es la paradoja de la política: que ella debe huir siempre y constantemente tanto de la homogeneidad completa como de la heterogeneidad extrema. Debe atenerse a lo que se presenta: el movimiento de la experiencia que sin parar es empujado de uno a otro extremo y a encontrar la sabiduría que le permita construir el "medio", el justo medio. Como ya lo preveía Aristóteles, esta sabiduría no se aprende en ningún lado sino en el campo de la experiencia real, viva y viviente de la interacción humana. Entre los extremos del conflicto puro y del consenso total hay que buscar el lugar propio de lo político y, por ende, de la filosofía de lo político.

Según Oliver Marchart ${ }^{36}$, el gran aporte de la filosofía de lo político del siglo XX es haber remarcado la "diferencia", más exactamente, y en principio, el haber traducido el tema heideggeriano de la "diferencia ontológica" en el tema, más radical y más concreto a la vez, de la "diferencia política". Teniendo en cuenta las reflexiones heideggerianas sobre el concepto de la diferencia ontológica (la diferencia Ser/ente, y sus distintas ramificaciones), Marchart nos aboca al tema de la diferencia en política. Se trata de la necesidad de reconocer la distinción entre dos esferas o dos dimensiones en la vida política, ya se llame la diferencia entre la política y lo político (o al revés), lo estatal y lo político, la "policía" y la política (Rancière ${ }^{37}$ ), etc. En todos los casos se puede entender como la diferencia irreductible entre las realidades políticas, empíricas e institucionales, efectivas (ónticas, se diría en lenguaje heideggeriano) y lo "político" como espacio de constitución originaria de lo social, como fundamento "ausente", pero eficaz en su ausencia, esto es, como una instancia cuasi-trascendental que ninguna determinación objetiva agota, aunque todas presuponen, y que remite únicamente a lo político-social como campo de heterogeneidad, contraposición, lucha, desacuerdo, o repartición no totalizable de las partes, etcétera. Esto es democracia, propiamente: el genio ilimitado e ilimitable del demos (del pueblo, de la comunidad). El "pueblo" nunca puede ser determinado en una única acepción, en un único sector, en una única representación; es lo abierto, plural e indeterminado por excelencia. Lo irrepresentable. Éste es el principio "cuasi-trascendental" de la democracia -que opera en lo real como el principio

${ }^{36}$ Cf. Oliver Marchart, El pensamiento político posfundacional. La diferencia política en Nancy, Lefort, Badiou y Laclau, Buenos Aires, FCE, 2009.

${ }^{37}$ Cf. Jacques Rancière, Política, policía, democracia, tr. María Emilia Tijoux, Ed. LOM, Santiago de Chile, 2006. 
crítico de la política-: el pueblo existe ante todo en estado virtual o "ideal" (como una multiplicidad pura), siempre se está realizando y nunca se realiza de forma última. Nadie puede hablar en su nombre, pero todas las voces dan cuenta de su realidad inagotable, de su potencia irreductible. Ahora bien, decimos cuasi-trascendental ( $y$ no trascendental), porque esta potencia (este poder como potencia), no permanece en una instancia meramente o puramente ideal (mental, eidética), porque es una instancia que, de alguna manera y en todo momento, se está expresando, deviene fenómeno: el "ser" irreductible, móvil, negativo en su movilidad, transición permanente que jamás puede ser agotada, fijada, abstraída, dominada o controlada...

Es la diferencia ontológica como diferencia política lo que la filosofía política y la filosofía en general han sido incapaces de observar; y lo han sido, en gran medida, porque aceptarla implica reconocer una dimensión irreductible a la filosofía y que, todavía más, la atraviesa a ella misma, imposibilitándole instalarse en definitiva en la posición del discurso neutro, abstracto, que pretende sobrevolar las vicisitudes de la condición de la existencia colectiva de los humanos y dictar desde fuera su verdad, su razón y su propósito. Es decir, el intento de escapar a la determinación política (como se dice: a la toma de posición) mediante la invención/ficción de un espacio apolítico. Por el contrario: nada de eso va a mantenerse en una concepción que asume la irreductibilidad, la contingencia y la novedad que significa el ser político en cuanto tal. "Ser" que, por otra parte, no habría que concebir como el puro lugar de la "no verdad", del caos, la violencia, el engaño o la manipulación, es decir, de la no-filosofía o de la antifilosofía sin más, sino, más bien, en los términos del último Maurice MerleauPonty, de la "a-filosofía", es decir, de aquello que por definición escapa a la filosofía pero a lo que ella está ineludiblemente avocada en cuanto "eso" contiene el secreto inhallable de su persistente búsqueda: es lo "otro" del pensamiento: la materialidad, la contingencia, el cuerpo, el mundo mismo; y que sólo una filosofía negativa, a la manera de la teología negativa (o de la dialéctica negativa de Theodor Adorno) puede darnos acceso - un acceso indirecto, en negativo o en "filigrana" -dice Merleau-Ponty. O, en sus propias palabras, y para concluir:

No se trata de una lucha entre filosofía y sus adversarios (positivismo), sino de una filosofía que quiere ser filosofía siendo no-filosofía - de una "filosofía negativa" (en el 
sentido de "teología negativa"), que se abre acceso a lo absoluto, no como "más allá", segundo orden positivo, sino como otro orden que exige el más-acá, el doble, no accesible más que a través de él -la verdadera filosofía se burla (se moque) de la filosofía, es afilosofía. ${ }^{38}$

${ }^{38}$ Maurice Merleau-Ponty, Notes de cours..., op. cit, p. 275.

| Investigaciones Fenomenológicas, n. 10, 2013. 